Research Article

\title{
Evaluation of Large-Scale Sports Project Based on Analytic Hierarchy Process
}

\author{
Jiewei Yang $\mathbb{C}$ \\ Huanghuai University, Zhumadian 463000, China \\ Correspondence should be addressed to Jiewei Yang; 20070835@huanghuai.edu.cn
}

Received 12 March 2021; Revised 25 April 2021; Accepted 15 May 2021; Published 24 May 2021

Academic Editor: Fazlullah Khan

Copyright $\odot 2021$ Jiewei Yang. This is an open access article distributed under the Creative Commons Attribution License, which permits unrestricted use, distribution, and reproduction in any medium, provided the original work is properly cited.

\begin{abstract}
When the evaluation system of regular sports events is applied to evaluating large-scale sports events, there is a shortage of the coverage rate of events evaluation and the low calculation precision of events economic evaluation index. This paper proposed the evaluation system of large-scale sports events based on the analytic hierarchy process. Firstly, we construct the evaluation system of large-scale events. Secondly, we determined the evaluation principles and evaluation procedures of events. The proposed model implies a fuzzy standard form system to get an optimal network structure, eliminate conflict rules, and trim nodes and links. The economic indicators of events are evaluated according to the content of events, such as financial cash flow, net present value, and profit margin of events. We also analyzed the evaluation of the content of social benefit and calculated the social impact assessment index to realize the evaluation of large sports events based on the analytic hierarchy process. According to the test data, the evaluation system's performance is better than the traditional evaluation system, and the coverage is increased by $47.85 \%$. The accuracy of the events economic evaluation index is improved by $32.45 \%$. It is more applicable to the evaluation of large-scale sports events.
\end{abstract}

\section{Introduction}

The evaluation system of regular sports events relies on the finite element analysis theory to evaluate the events. During the evaluation process of large sports events, the data amount is far greater than the analysis sample. The coverage rate of events evaluation is low, and the economic evaluation index's calculation accuracy is low [1]. At present, there is a difference between industry and department in China's project evaluation. The difference between industry and department leads to different evaluation standards. One is the analysis of the social economy promoted by large-scale sports events in the national economic evaluation; that is, the measurable benefit for society has been considered in the national economic evaluation. At the same time, it also includes the nonmeasurable aspects of the social economy [2]. The former is mainly quantitative analysis, and the latter emphasizes qualitative analysis. The second difference is the analysis of the negative effects of social benefits, mainly the consumption of resources and the environment's cost during large-scale sports events. If large-scale sports events can promote social-economic benefits, but the cost of resource utilization and environmental protection is higher than the social income, the sports events failed [3]. Toward this speculation, an evaluation system of large-scale sports events based on the analytic hierarchy process is proposed in the research work.

The evaluation system of large-scale sports events is established, the systematic principle, objectivity principle, and benefit principle of evaluation are determined, and the evaluation procedure is established. The balance of profit and loss is determined according to the events' financial cash flow and operating cost [4]. The financial evaluation of events is realized for completing the evaluation of national economic benefits based on the net present value. The design of the fuzzy paradigm system enables learning to be maintained at a good level. In the system's operation, the network is tested on the integrated data set and the actual data set, and good performance is obtained [5]. The social impact assessment content is illustrated to determine the 
evaluation index of social impact and realize the research on the evaluation system of large-scale sports events based on the analytic hierarchy process [6].

In this research paper, we proposed a fuzzy model. The proposed model analyzes the relationship between classes to secure the integrity of the subclass. For example, the paper introduces the design level of integrity and authentication scheme and analyzes its characteristics. The security and efficiency of the proposed model and credibility analysis showed that the established model could guarantee the security of medical health data integrity verification scheme and can guarantee the credibility of the data source. To ensure the evaluation system's effectiveness, the test environment of large-scale sports events is simulated [7]. Two different evaluation systems are used to obtain the accuracy of evaluation coverage and economic evaluation index. The evaluation system's performance is better than the traditional evaluation system, and the coverage is increased by $47.85 \%$. The accuracy of the events economic evaluation index is improved by $32.45 \%$. The results show that the proposed evaluation system is highly effective [8].

The rest of the paper is presented as follows: construction of the evaluation system for large-scale sports events is explained in section 2 , a realization of the evaluation system of large-scale is discussed in section 3, and similarly, in section 4, experimental results and discussion are discussed. Finally, we demonstrate a conclusion and future work.

\section{Construction of the Evaluation System for Large-Scale Sports Events}

This section discusses the determination of large-scale sports events' evaluation principles and the determination of the evaluation procedure for large-scale sports events.

\subsection{Determination of Evaluation Principles of Large-Scale} Sports Events. The evaluation principles of large-scale sports events must abide by the principles when evaluating the social and economic impacts of sports events, i.e., systematic principle, objectivity principle, standardization principle, and the principle of dynamic ordering. Large sports events are treated as a project group [9]. From the perspective of modern management theory, it is a system of multifaceted operations. At the same time, it is subordinate to society, nature, and the market. Internal systems always have to be coordinated with external systems for production, survival, and development. Suppose that the evaluation of large sports events is separated from society and the market. In that case, the evaluation will lose fairness, and it cannot accurately reflect the real role of large-scale sports events [10]. Adhering to the systematic principle is to make the largescale sports events combine the financial benefits with the macroeconomic and society in the evaluation process and get a conclusion and feedback of the decision. The evaluation function that is reflecting the systematical principle:

$$
\delta=\frac{1}{L-l} \sum_{i=1}^{j} \frac{S F^{2}}{d h},
$$

where $\delta$ represents the principle of systematic evaluation. $L$ represents large-scale sports events. $S F$ represents financial benefits and macroeconomic factors. $D$ represents the social impact index. $H$ represents the social benefits of events.

Similarly, objectivity is to follow the objective law, seek truth from facts, and be fair and scientific in evaluating largescale sports events [11]. Adhering to the principle of objectivity, first, this requires from the evaluator to avoid all kinds of preconceived ideas and overcome subjective arbitrariness and unilateralism. Second, the evaluator should thoroughly investigate and grasp reliable information comprehensively and systematically. It is the basic requirement to adhere to objectivity and the basic guarantee of the scientific nature of evaluating large-scale sports events. The standardization principle is that the qualitative and quantitative analysis methods adopted in the evaluation work must conform to the state regulations and must be scientific. The standardized evaluation system of large-scale sports events constitutes the stable structure and basic evaluation discipline content. Generally, standardized methods do not affect the evaluators' creative work but are necessary for the creative work to be admitted [12, 13]. Sports events are complex project groups, especially the top events such as the Olympic Games. From the beginning to the successful end of the Olympic Games, the length of its cycle is unparalleled. Therefore, the entire project should be completed sequentially, and the relevant evaluation has to be carried out at each stage of the implementation in organized order [14].

\subsection{Determination of the Evaluation Procedure for Large-Scale} Sports Events. Large sports events are complex project groups. We can treat them as a system. Large sports events involve not only the economic subsystem, but also the environmental subsystem and social subsystem. The three have to intersect, but they are independent aspects, as shown in Figure 1 [15]. In view of the system, any system must have three common things: one is integrity; another is that the system must be composed of elements of interdependence and interaction; thirdly, the system is affected and interfered with by the environment, and the environments (natural environment and social environment) interact with each other. Under certain conditions, it plays a decisive role in the system's existence and development [16]. The process flow of the evaluation of sports events is shown in Figure 2.

\section{Realization of the Evaluation System of Large- Scale Sports Events}

For large-scale sports events, the life cycle is divided into the preparation stage, the implementation stage and operation stage, and the posteffect stage of sports events. The corresponding evaluation of each step is the preevaluation, the tracking evaluation, and the postevaluation of sports events [17]. As the social and economic benefits of large-scale sports 


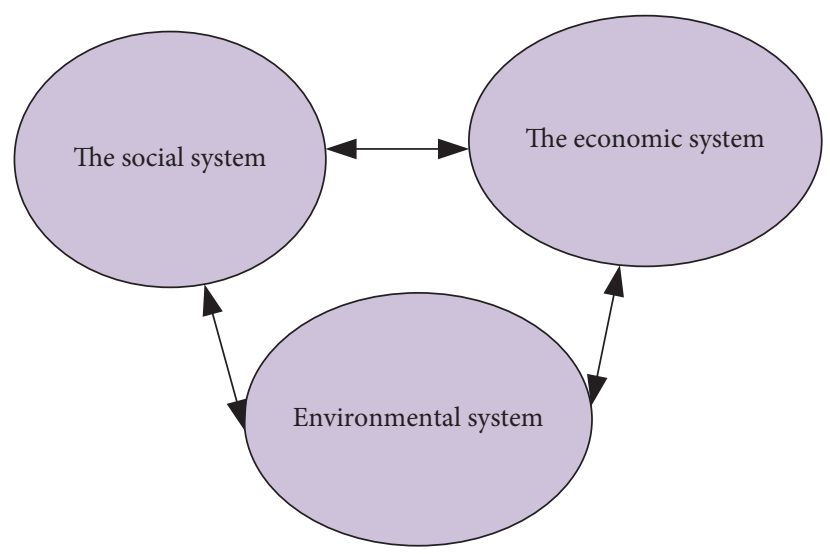

Figure 1: Relationship diagram of a social, economic, and environmental system.

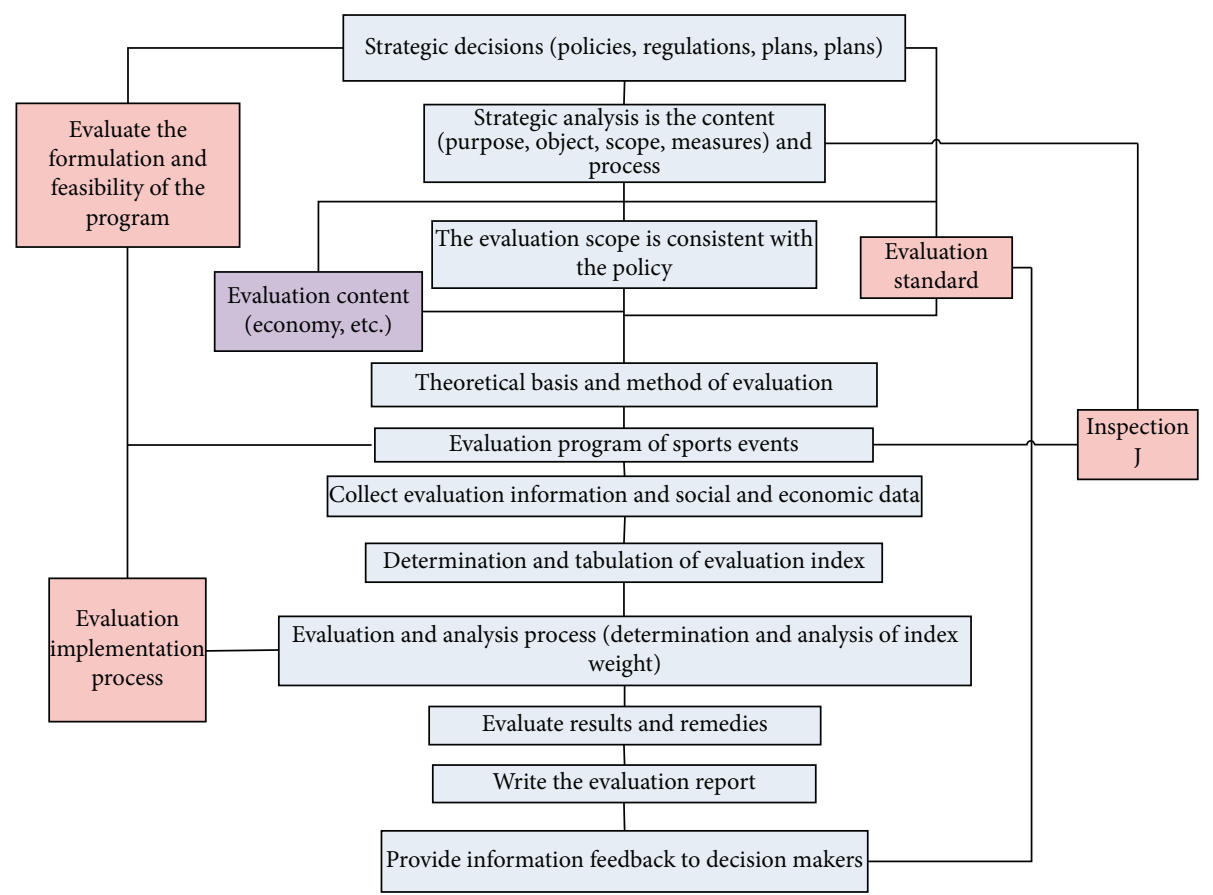

Figure 2: The process flow of evaluation of large-scale sports events.

events are mainly produced in the implementing stage of sports events and the posteffect stage of sports events, this section explicitly studies the social and economic effects of significant sports events during the event.

\subsection{Evaluation and Index Calculation of Economic Evaluation} of Large-Scale Sports Events. One of the main objectives of large-scale sports events is to obtain certain economic benefits. Therefore, the economic evaluation is an essential part of the assessment of large-scale sports events. The economic evaluation of large-scale sports events is the same as the economic evaluation of other projects, including the financial review of large-scale sports events and the national economic evaluation of large-scale sports events, respectively, from the micro- and macropoint of view to analyze sports events [18]. The scope of the economic evaluation of large-scale sports events is from the hosting organization's point of view. According to the state's current financial and tax policy, sports events' economic evaluation is mainly evaluated and analyzed from the cost and income points of view. The national economic large-scale sports assessment events analyze and calculate the contribution of large-scale sports events to society and the national economy from the state and society's perspective. The implementation and operation of large-scale sports events transform logistics, information flow, and capital flow. Financial performance is a certain amount of capital flow, from capital investment to the recovery, and appreciation of wealth in the end. The economic evaluation of sports events is based on reviewing the cost and profit of capital flow in sports events' implementation process [19]. However, sports events' economic 
evaluation must be under the current financial and tax policy and price system. If it is from the host's standpoint to study sports events' financial situation and evaluate the cost and income of each stage of sports events, the current laws and regulations must be observed.

The economic evaluation of major sports events is by calculating the financial benefits and expenses directly occurring in sports events, examining the financial situation of the profitability, compensation ability, and foreign exchange balance ability of sports events. Finally, sports events' economic conclusions are concluded, and information support for the sports event organizing project's decision-making is provided. The interests of all parties involved in sports events should be taken into account. Therefore, the role of economic evaluation in sports events has three aspects: one is to reflect the profitability of sports events and the ability to repay debt, to clarify the benefits obtained by the investors and the security of the investment funds, and to provide information support for the investment decision of the investors (creditors); two is to provide information and data for the cost management of sports events, including the scale of the investment required for sports events, the planning, and fundraising schemes for the use of money, all of which are the essential contents of the economic evaluation; the third is to analyze and determine the risk and countermeasures of the investment in sports events. There are financial risks in sports events and other projects, including risk costs and project benefits, which all need to be analyzed and determined through the economic evaluation of sports events.

The analysis of sports events' cash flow requires the whole course of sports events to be considered an independent financial system. Then, a comprehensive analysis is made on the situation of cash inflow and cash outflow in the calculation period of sports events, which is the primary data of the calculation of the economic evaluation index of sports events. The cash flow of large-scale sports events refers to the general term of cash inflow and cash outflow, directly related to sports events during the calculation period. Generally, at the same time point, the cash inflow of sporting events is positive, and the relative cash outflow is negative. Taking significant sports events as a project, the main elements of the economic evaluation's cash flow include the investment of sports events, the operating costs of sports events, sales income tax, and profit rate. The investment composition of large-scale sports events is shown in Figure 3.

\subsubsection{Total Cost of Economic Evaluation of Large-Scale Sports} Events. In the economic evaluation of large-scale sports events, the cash outflow in sports events' operating period is mainly its operating cost. It is the sum of all the costs and expenses incurred in sports events from the beginning to the end of the event. The total cost of sports events is calculated according to the cost items of sports events. The formula is as follows:

$$
F=F_{0}+\sum_{i=1}^{j}\left(C_{i}+R_{i}+T_{i}+J_{i}\right)
$$

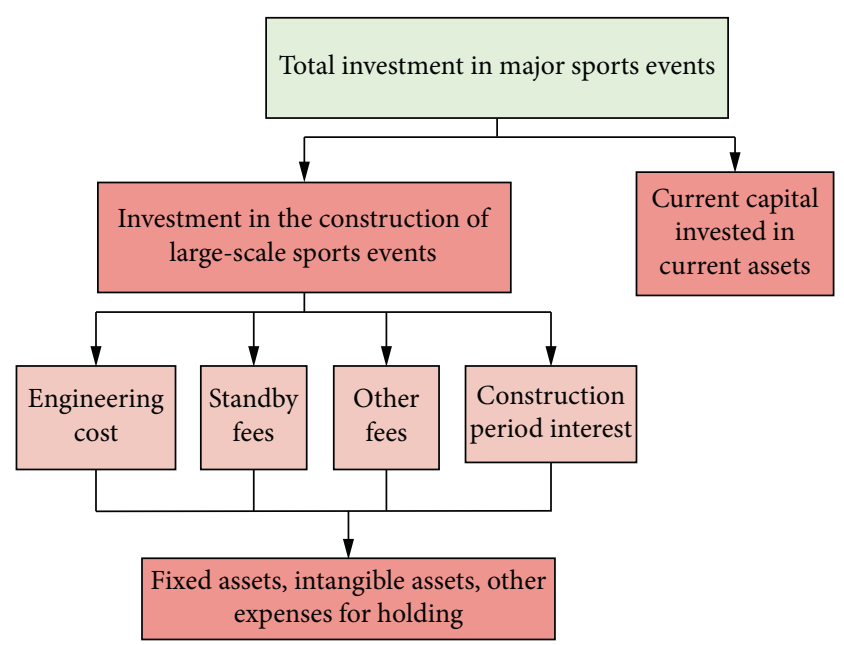

FIgURE 3: The investment composition of large-scale sports events.

$F$ represents the total cost, $F_{0}$ stands for the essential cost, $C_{i}$ represents sales, $R_{i}$ represents the media cost, $T_{i}$ represents the management cost, and $J_{i}$ represents the financial cost. The above formula's critical price includes the construction of the primary venues, the cost of the transformation (including the labor cost), and the related equipment's purchase cost. The sales and media price includes the expenses of the sports events, the tickets, the expenses for the sale of the corresponding service souvenirs, the cost of management, and the financial cost, which is the total cost consumed during the event.

\subsubsection{The Operating Cost of Large-Scale Sports Events.} The operating cost of large-scale sports events is part of the total cost. It mainly refers to the cost that the sports events pay during the sports events to meet the regular order of sports events. This stage is the main stage of cash outflow in the whole process of sports events. Therefore, the operating cost of sports events can also be considered part of the total cost paid in cash; that is, the part not paid in cash, including the transfer value of long-term assets, like depreciation expense, is removed from the total cost. Although depreciation expense is the consistent content of the accounting cost, from the whole running cycle of sports events, it belongs to the apportionment of fixed assets and intangible assets that have been paid in cash. Therefore, when calculating the cash flow of sports events, depreciation expenses can no longer be regarded as expenditures. Otherwise, there will be repeated calculations. Besides, interest expenditure is a worthwhile expenditure of sports events. Still, from the point of view of investment (private capital and debt fund), the interest is an essential part of investment income. So, it should not include interest expenditure in the operating cost of sports events. Therefore, in analyzing the relationship between operating expense and total cost, we can get the operational cost formula:

$$
F_{y}=F-\frac{\partial F_{x} d x}{F}-\Delta \xi
$$


$F_{y}$ represents the operating cost, $F$ represents the total cost, and $F_{x}$ represents depreciation expense, and $\Delta \xi$ is interest expense.

3.1.3. Benefits of Large-Scale Sports Events. The benefits of large-scale sports events are obtained from the sale of events. The benefits of sports events are not equal to the profits of sports events. The profits of sports events are affected by the benefits, costs, and taxes of sports events. Sales of sports events include a wide range of sales revenue, such as sales of tickets, sales of broadcasting rights, and sales of commemorative coins and souvenirs. These are major cash inflow subjects during sports events. Tax is the tax money that is included in the sales revenue. The main taxes are consumption tax, urban construction tax, income tax, and operation tax. Apart from taxes, the hosting organization is more concerned about the profits generated by sports events. Therefore, the formula for calculating the sales revenue of large-scale sports events can be expressed in this way.

$$
S=\Delta b+C_{z}+C_{S}+\Delta S .
$$

In the formula, $S$ represents sales revenue, $\Delta b$ represents profits, $C_{Z}$ represents the total cost of events, $C_{S}$ represents tax, and $\triangle S$ represents other surcharges. The economic evaluation method of large-scale sports events is linked to financial evaluation's purpose and content. Therefore, to evaluate the profitability of the financial profit level of sports events, there are dynamic profit analysis and static profit analysis based on cash flow and the ratio analysis of financial statements by preparing the profit and loss statement. The evaluation of solvency is to calculate the repayment period of the loan through the source of funds and the use of cash flow. The corresponding financial ratio is calculated from the balance sheet; the foreign exchange balance evaluation is calculated from the "foreign exchange surplus" item in the foreign money exchange balance sheet. It is used to examine the balance of the internal and external remittance in sports events' calculation period. In addition to the direct analysis of financial statements used in foreign exchange balance evaluation, other methods need to calculate one or more financial evaluation indicators. Several economic evaluation indicators for large-scale sports events are shown in Figure 4.

Profit and loss balance analysis of sports events is a method of analysis and evaluation from the financial perspective to evaluate sports events' status. The analysis of profit and loss of sports events is based on analyzing the relationship between the operating cost and the profit of sports events, to find the critical point of the program's profit and loss, and judging the influence of the uncertain factors on the economic effect of the sports events operation scheme, to explain the risk of implementing the sports event. This critical point is called the breakeven point (BEP), as shown in Figure 5.

BEP represents the profit and loss balance point of sports events operation in the curve, and $S$ represents the income of sports events operation. $Q$ represents the value of sports event operation output in quantity. $Q_{1}$ represents the value of sports event operation output in the BEP, cost, and fixed cost of sports events operation by $C$ and $C_{1}$, respectively. From the above figure, it can be concluded that, above the $\mathrm{BEP}$, the revenue line and the total cost line constitute the profit area of sports events. Above the BEP, the area is made up of the income line, and the total cost line is the profit area for the sports events. Under the total cost line, it is the total cost area of the sports event operation, including the variable capital and the fixed capital of sports events.

3.1.4. Analysis and Evaluation of the Cost of National Economic Benefit. The national economic benefit-cost analysis of large-scale sports events mainly focuses on the cost flow of the federal financial benefit in the calculation period to investigate the total contribution to the national economy. The leading indicators are economic net present value, economic net present value rate, and internal rate of return. Large-scale sports events convert the economic net present value into the sum of the base stage's present value during the calculation period by using the social discount rate. The concrete formula is as follows:

$$
\mathrm{ENPV}=\sum_{i=1}^{n}\left(C_{I}-\mathrm{CO}\right)_{t}\left(1+i_{s}\right)^{-t},
$$

where $C_{l}$ is the benefits flow; $\mathrm{CO}$ is the cost flow; $\left(C_{I}-\mathrm{CO}\right)$ is the annual net benefit flow; $i$ is the social discount rate; $n$ is the calculation period. The economic net present value of large-scale sports events is an absolute index reflecting significant sports events' net contribution to the social economy. Suppose that the economic net present value of the large-scale sports event is greater than zero. In that case, it shows that the event compensates for all the national financial investment and has a certain excess surplus. It proves that the event can be carried out and promoting the host city's national economy. When the event's economic net present value is equal to zero, indicating that the event can compensate for the federal financial investment, there is no excess surplus. It is a marginal event, and it can be considered feasible if it contributes to other aspects such as raising public sports facilities. Still, if the economic net present value is less than zero, it is not beneficial for the national economy.

The economic net present value rate of significant sports events is a ratio index of the net present value of the investment project's national economy and its total discount investment according to society's discount rate. In selecting sports event plans, if programs' investments are equal, the economic net present value index can be used for comparative selection. In general, if the economic net present values of various sports events are not equal, it is necessary to combine them with the economic net present value rate. The calculation formula is as follows:

$$
\mathrm{ENPVR}=\frac{\mathrm{ENPV}}{E I_{P}} .
$$

Among them, $E I_{P}$ is the sum of the present value of the total investment discounted with society's discount rate in the project. The economic net present value rate of large sports events indicates the relative number of economic net present value generated by the present value of the hosting 


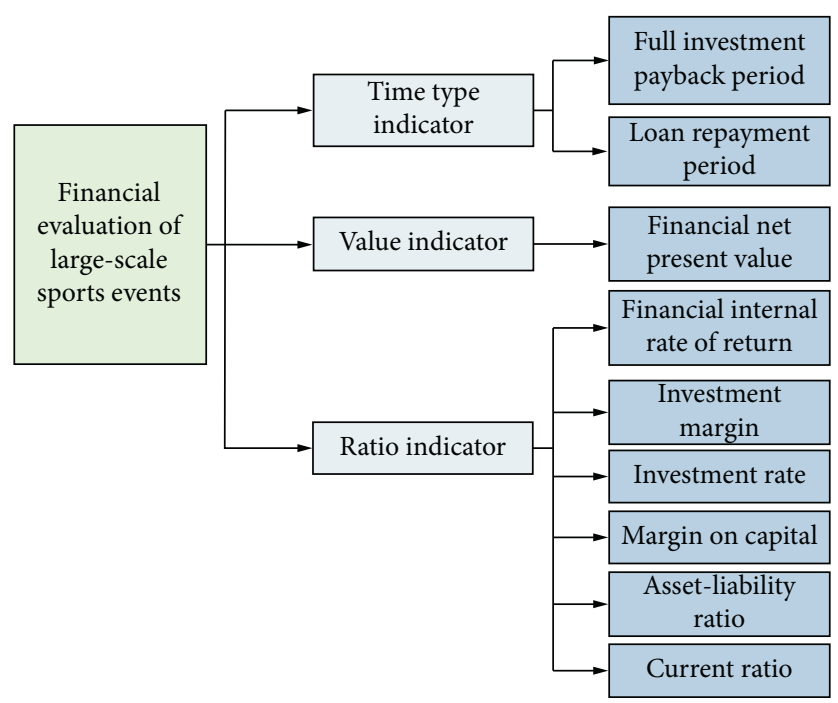

FIGURE 4: Economic evaluation index system for large-scale sports events.

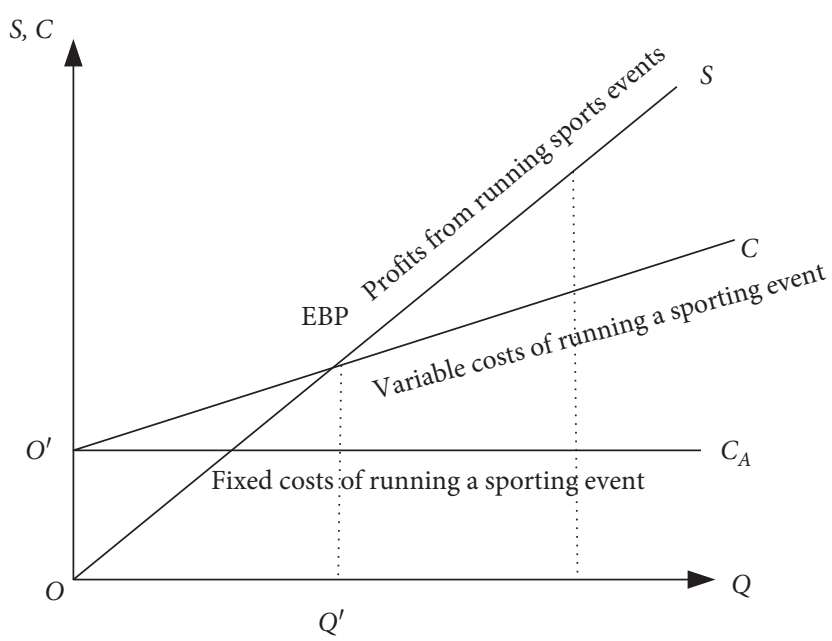

Figure 5: Profit and loss balance of large-scale sports events.

organization's investment amount. The project's economic net present value is first required to be greater than zero or equal to zero in the single evaluation. Secondly, when the competition scheme is selected, the project with a higher economic net present value rate should be chosen to carry out. The maximization of the economic net present value rate is conducive to the optimal utilization of funds. It is a relative evaluation index in the national economic evaluation of large-scale sports events, and its expression formula is

$$
\sum_{t=1}^{n}\left(C_{I}-\mathrm{CO}\right)_{t}(1+\mathrm{EIRR})^{-t}=0 .
$$

The calculation method of the internal rate of return for sports events is the same as the calculation method of the internal rate of return. The calculation formula is as follows:

$$
\operatorname{EIRR}=I_{1}+\left(I_{2}-I_{1}\right) \frac{\left|\mathrm{ENPV}_{1}\right|}{\left|\mathrm{ENPV}_{1}\right|+\left|\mathrm{ENPV}_{2}\right|} .
$$

$I_{1}$ represents the low discount rate of trial calculation; $I_{2}$ represents the high discount rate of trial calculation; ENPV is the economic net present value (positive value) of a low discount rate. The ENPV 2 is the economic net present value (negative value) of a high discount rate, and formula 11 is brought to formula 12 ; there is

$$
\sum_{t=1}^{n}\left(C_{I}-\mathrm{CO}\right)_{t}\left[1+I_{1}+\left(I_{2}-I_{1}\right) \frac{\left|\mathrm{ENPV}_{1}\right|}{\left|\mathrm{ENPV}_{1}\right|+\left|\mathrm{ENPV}_{2}\right|}\right]^{-t}=0
$$

The internal economic rate of return of large-scale sports events is a relative evaluation index reflecting the contribution of sports events to the national economy. According to the characteristics of the internal rate of return of sports events, if the internal rate of return is greater than the social discount rate, and the economy's net present value is greater than zero, it is economically feasible to hold sports events, and its holding can promote economic development. On the 
contrary, if the internal rate of return is less than the social discount rate, and the net present value of the economy is less than zero, the holding of sports events is a failure. Among the above two cases, the internal rate of return is equal to the social discount rate, and the net present value of the economy is equal to zero. The event is defined as a marginal project. Whether the event is held depends on the influence brought by the sports events on other aspects. The economic benefit evaluation process of large-scale sports events is the use of a financial profit ratio to calculate the national economy's profit in the period of significant sports events. The main evaluation index is the net benefit rate of investment. The net benefit rate of large-scale sports events is a proportional index. It examines the economic profitability of sports events in normal conditions and directly reflects the net contribution of sports events to the national economy. The net benefit of sports investment should be equal to the federal net income minus staff's cost and welfare during the sports event. Its calculation formula is

$$
\mathrm{NBR}=\frac{\left(C_{I}-\mathrm{CO}\right)}{I} .
$$

The formula $\left(C_{I}-\mathrm{CO}\right)$ is the economic benefit flow in the normal year, where " $I$ " is the total investment in sports events (including the investment and circulating funds of the venues).

3.2. Content and Index Calculation of Social Impact Assessment for Large-Scale Sports Events. The evaluation of the social impact of sports events aims to systematically investigate the effect and social benefits of production and reproduction of sports events to society and analyze the adaptability and acceptability of the host city's social environment. The purpose is to coordinate the national economy and society's development and coordinate sports events and host cities' interests. Employment indicators naturally become the primary indicator to evaluate the social impact of sports events.

$$
J=\frac{D}{\sum g h d x}
$$

In the format, $J$ represents the employment effect index, and $D$ represents a new increase in total employment, which includes sports events themselves and related industries, and $g h$ indicates direct investment $(g)$ and indirect investment $(h)$ included in the total investment. The employment-population caused by sports events can be divided into two categories. One is the increase in the employment-population of sports events. The second is the employment of other related industries. Therefore, the employment index of sports events can be decomposed into two indicators, as shown in

$$
\left\{\begin{array}{l}
R_{z}=\frac{D}{g}, \\
R_{j}=\frac{D_{f}}{g+g^{\prime}} .
\end{array}\right.
$$

In the formula, $R_{Z}$ represents the number of direct employment in sports events, and $D$ represents the number of new employment in sports events, $g$ represents a direct investment in sports events, with a unit of 10000 yuan, $R_{j}$ represents the number of indirect employment in sports events, and $D_{f}$ represents the number of new employment in related industries. $\left(g+g^{\prime}\right)$ represents the investment in related industries, with a unit of 10000 yuan. The allocation indicator of sports events is to test whether the distribution of economic benefits of sports events in the country, region, and distribution is reasonable. The calculation formula is as follows:

$$
\left\{\begin{array}{l}
G_{b}=\frac{A_{g}}{e+i} \\
D_{b}=\frac{A_{d}}{e+i} .
\end{array}\right.
$$

In the formula, $G_{b}$ represents the proportion of national income, $A_{g}$ represents the profit of the state finance, $e$ represents the profit of sports events, $i$ represents tax, $D_{b}$ represents the local benefit ratio, and $A_{d}$ represents the profit donated to local finance by sports events.

\section{Experimental Results and Analysis}

The feasibility analysis of the large-scale sports project was proposed to carry on the simulation analysis and the sports project appraisal. In the experiment, sports events of different scales are taken as the test object to carry out the accuracy simulation test of evaluation coverage and economic evaluation index. The different types of sports events and the number of people watching events are simulated. We used the conventional evaluation system as the control group and compared the results of two simulation experiments to ensure the investigation's effectiveness. The experimental data were presented in the same data graph.

4.1. Data Preparation. In this paper, sports events of different scales are used as test objects in the process of simulation tests, and two different evaluation systems are used to carry out simulation tests and evaluations of coverage and economic evaluation indexes. The purpose is to ensure the accuracy of simulation in the test process by analyzing the simulation experiment. The analysis results obtained by different methods during the investigation are different, so it is necessary to ensure that the experiment's environmental parameters are the same. The experimental data of this paper are shown in Table 1.

Considering the simulation test process's fairness, the same configuration simulation equipment and simulation source are selected for two different evaluation systems, and Table 2 specifies the simulation equipment parameters.

4.2. Analysis of Test Results. In the experiment, two different evaluation systems are used to analyze and evaluate the 
TABLE 1: Test parameters setting.

\begin{tabular}{|c|c|c|c|c|}
\hline Serial number & Event type & Number of participants & The total number of people & Duration/week \\
\hline 1 & Track and field & 24152 & 254484 & 2 \\
\hline 2 & Badminton & 21465 & 512214 & 2 \\
\hline 3 & Softball & 12657 & 123154 & 2 \\
\hline 4 & Basketball & 12687 & 146512 & 3 \\
\hline 5 & Football & 25694 & 156847 & 2 \\
\hline 6 & Boxing & 12589 & 325448 & 2 \\
\hline 7 & The bicycle & 12664 & 262445 & 3 \\
\hline 8 & Gymnastics & 36548 & 132484 & 2 \\
\hline 9 & Hockey & 12656 & 556154 & 3 \\
\hline 10 & Table tennis & 12365 & 234545 & 2 \\
\hline
\end{tabular}

TABLE 2: Test parameters setting.

\begin{tabular}{lcc}
\hline Project & Type parameters & Version parameter \\
\hline The operating system & Windows & 7 Ultimate \\
Central processing unit & AMD Ryzen $72700 \mathrm{X}$ & $\mathrm{CPU}$ main frequency: $3.7 \mathrm{GHz}$ \\
The sound card & Sound with D1 & Maximum frequency: $4.3 \mathrm{GHz}$ \\
& & $88.2 \mathrm{kHz}, 24 \mathrm{bit}$ \\
The graphics card & NVIDIA TITAN V & Video memory capacity: $12 \mathrm{~GB}$ \\
& & Display memory bit width: 3072 bit \\
& Core frequency: $1200 / 1455 \mathrm{MHz}$ \\
Memory chips & Display frequency: $1700 \mathrm{MHz}$ & Memory type: DDR4 \\
& AstraZeneca X3 16 GB DDR4 2400 & Main memory frequency: $2400 \mathrm{MHz}$ \\
& & Memory capacity: $16 \mathrm{~GB}$ \\
\hline
\end{tabular}

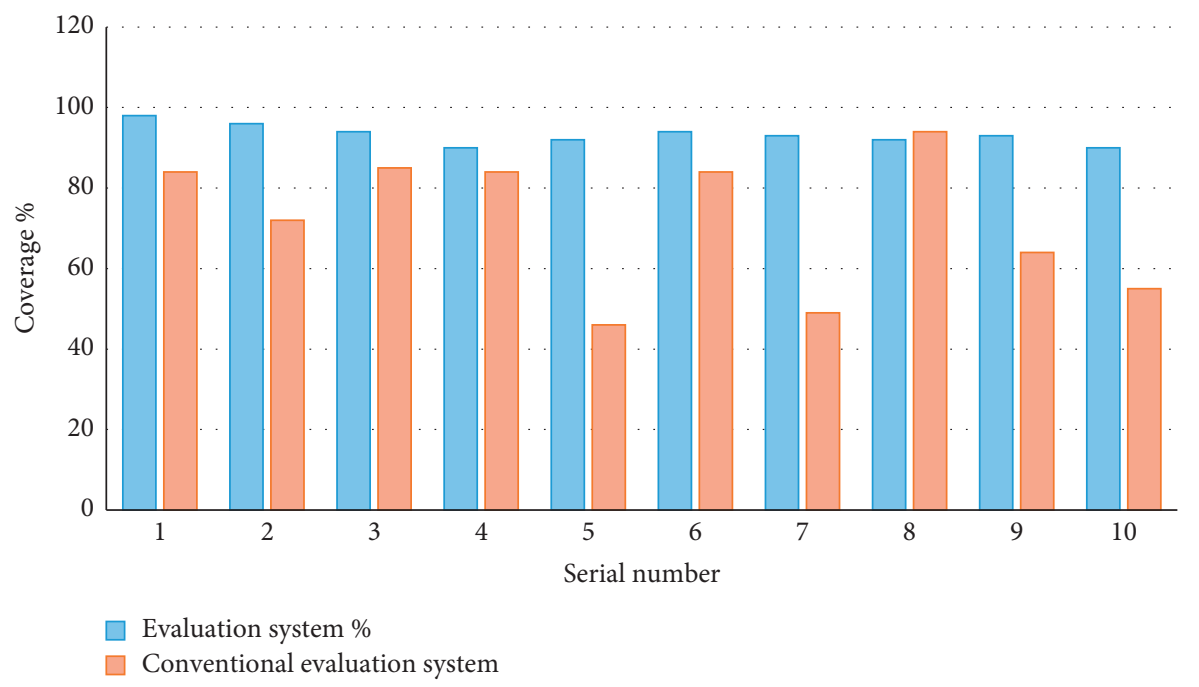

Figure 6: Comparison of results of coverage test.

accuracy changes of coverage and economic evaluation indexes. At a particular time, the analysis results cannot be directly compared because of two different evaluation systems. For this purpose, an analysis (third-party analysis recording software) is used to record and analyze the experimental process and results in detail, and the resulting curve reflects the experimental results. In the curve resulting from simulation tests, the uncertainty caused by computer equipment factors in simulation tests and human operation is eliminated through analysis. The accuracy simulation test of evaluation coverage rate and the economic evaluation index is carried out only aimed at sports events of different scales and different evaluation systems. The comparison curve of experimental results is shown in Figure 6.

According to the experimental results, the proposed evaluation system's average coverage and the conventional evaluation system are obtained using analysis. The proposed evaluation system's coverage rate is $47.85 \%$ higher than that of the traditional evaluation method. Then, the accuracy test is carried out, and the comparison result of the calculation accuracy test is shown in Figure 7. 


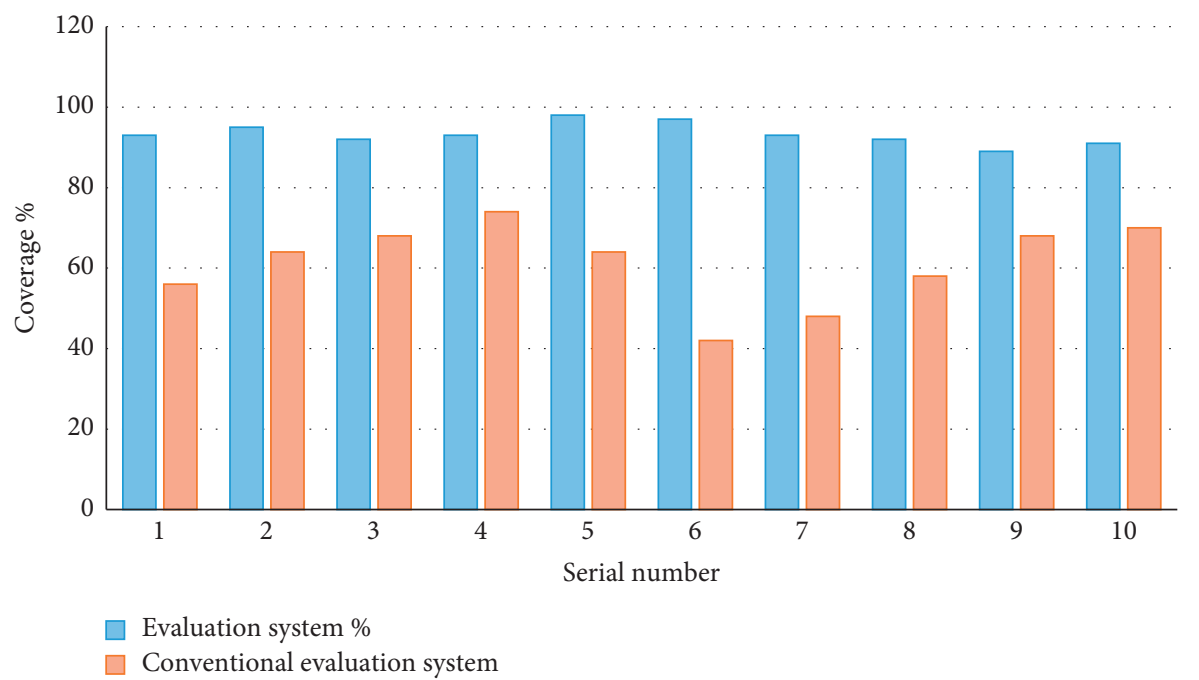

Figure 7: Comparison results of calculation accuracy test.

It is concluded that the proposed evaluation system is $32.45 \%$ better than the conventional evaluation system, which is suitable for large-scale sports events.

\section{Conclusion}

This study yielded an evaluation system for large-scale sports projects under the analytic hierarchy process. It is based on the analytical hierarchy process, the evaluation principles, and evaluation procedures of large-scale sports events. It also uses the calculation of the content and index of the evaluation of significant sports events. The experimental results exhibit that the performance of the proposed scheme is feasible. In the future, this study can provide the theoretical basis for the evaluation system of large-scale sports events.

\section{Data Availability}

The datasets used and/or analyzed during the current study are available from the corresponding author upon reasonable request.

\section{Conflicts of Interest}

The author declares that there are no conflicts of interest.

\section{Acknowledgments}

This work was supported by Henan Higher Education Teaching Reform Planunder Project (no. 2019SIGLX422).

\section{References}

[1] Y. Zhou, L. Wang, "Multilevel fuzzy comprehensive evaluation method based on cloud model theory," Computer Simulation, vol. 33, no. 12, pp. 390-395, 2016.

[2] S. Duan, W. Jun, "Research and simulation on vehicle selforganizing network communication performance optimization," Computer Simulation, vol. 33, no. 4, pp. 336-339, 2016.

[3] H. Zhao, X. Wang, S. O. Management et al., "Research on dynamic financing risk evaluation system of large-scale infrastructure projects," Journal of Beijing Institute of Technology, vol. 5, no. 10, pp. 41-44, 2017.

[4] M. Galetto, L. Mastrogiacomo, D. Maisano, and F. Franceschini, "Uncertainty evaluation of distributed LargeScale-Metrology systems by a Monte Carlo approach," CIRP Annals, vol. 65, no. 1, pp. 491-494, 2016.

[5] J. Zhou, H. Liu, Y. Liu et al., "Development and evaluation of a parallel reaction monitoring strategy for large-scale targeted metabolomics quantification," Analytical Chemistry, vol. 88, no. 8,2016

[6] J. Sligo, R. Gauld, V. Roberts, and L. Villa, "A literature review for large-scale health information system project planning, implementation and evaluation," International Journal of Medical Informatics, vol. 97, pp. 86-97, 2017.

[7] S. A. Ghoreishi-Madiseh, A. P. Sasmito, F. P. Hassani et al., "Performance evaluation of large-scale rock-pit seasonal thermal energy storage for application in underground mine ventilation," Applied Energy, 2016.

[8] C.-C. Chou, P.-T. Chung, and Y.-T. Cheng, "Experimental evaluation of large-scale dual-core self-centering braces and sandwiched buckling-restrained braces," Engineering Structures, vol. 116, pp. 12-25, 2016.

[9] J. Gao and M. Bergés, "A large-scale evaluation of automated metadata inference approaches on sensors from air handling units," Advanced Engineering Informatics, vol. 37, pp. 14-30, 2018.

[10] D. Förster, H. Löhr, A. Grätz et al., "An evaluation of pseudonym changes for vehicular networks in large-scale, realistic traffic scenarios," IEEE Transactions on Intelligent Transportation Systems, no. 99, pp. 1-6, 2017.

[11] B. Lct, M. López-Ibáñez, and T. Stützle, "A large-scale experimental evaluation of high-performing multi- and many-objective evolutionary algorithms," Evolutionary Computation, no. 2, p. 1, 2017.

[12] G. Castignani, T. Derrmann, R. Frank et al., "Smartphonebased adaptive driving maneuver detection: a large-scale evaluation study," IEEE Transactions on Intelligent Transportation Systems, no. 99, pp. 1-10, 2017.

[13] V. A. Semenov and E. A. Cherenkova, "Evaluation of the atlantic multidecadal oscillation impact on large-scale Atmospheric circulation in the atlantic region in summer," Doklady Earth Sciences, vol. 478, no. 2, pp. 263-267, 2018. 
[14] G. Horvat, D. Zagar, and J. Vlaovic, "Evaluation of quality of service provisioning in large-scale pervasive and smart collaborative wireless sensor and actor networks," Advanced Engineering Informatics, vol. 33, 2016.

[15] H. Mikulčić, E. V. Berg, M. Vujanović et al., "Numerical evaluation of different pulverized coal and solid recovered fuel co-firing modes inside a large-scale cement calciner," Applied Energy, vol. 184, pp. 1292-1305, 2016.

[16] T. Vetter, J. Reinhardt, M. Flörke et al., "Evaluation of uncertainty sources in projected hydrological changes under climate change in 12 large-scale river basins," Climatic Change, vol. 141, pp. 1-15, 2017.

[17] N. Usman, S. Usman, F. Khan et al., "Intelligent dynamic malware detection using machine learning in IP reputation for forensics data analytics," Future Generation Computer Systems, vol. 118, no. 2, pp. 124-141, 2021, Early Access.

[18] H.-J. Shin, W.-J. Kwak, D. Aurbach, and Y.-K. Sun, "Largescale Li-O2Pouch type cells for practical evaluation and applications," Advanced Functional Materials, vol. 27, no. 11, Article ID 1605500, 2017.

[19] C. Feng, J. Xu, X. Yang et al., "Stackelberg-Nash equilibrium for integrated gravelly soil excavation-transportation-distribution system in a large-scale hydropower construction project," Journal of Computing in Civil Engineering, vol. 30, no. 6, 2016. 